\title{
Perguntas de leitura na prática docente em sala de apoio $^{1}$
}

\section{Reading Questions in Teaching Practice in a Support Classroom}

\author{
Cristiane Malinoski Pianaro Angelo* \\ Universidade Estadual de Maringá; Universidade Estadual do Centro-Oeste \\ Maringá - Paraná / Brasil \\ Renilson José Menegassi** \\ Universidade Estadual de Maringá \\ Maringá - Paraná / Brasil
}

\begin{abstract}
RESUMO: Neste artigo, aborda-se a construção de perguntas de leitura na prática docente em uma Sala de Apoio à Aprendizagem de Língua Portuguesa (SAALP) - $6^{\circ}$ ano do Ensino Fundamental, na região Centro-Sul do Estado do Paraná. A partir dos conceitos relacionados ao dialogismo do Círculo de Bakhtin e das contribuições da Linguística Aplicada, buscou-se orientar e acompanhar a prática de um professor de SAALP na elaboração de perguntas de leitura. A coleta de dados deu-se anterior e posteriormente a intervenções teórico-metodológicas de modo colaborativas com o docente, propiciando-lhe aportes teóricos e discussões orientadas a respeito das concepções e das etapas do processo de leitura e suas implicações no ensino e na aprendizagem da língua materna. Os resultados apontam a necessidade de se fornecer ao professor de SAALP subsídios teórico-metodológicos a respeito do processo da leitura, bem como acompanhar e orientar a sua prática pedagógica na elaboração de perguntas de leitura nesse contexto de ensino específico.
\end{abstract}

PALAVRAS-CHAVE: perguntas de leitura, Sala de Apoio à Aprendizagem, formação docente continuada.

ABSTRACT: This paper discusses the preparation of reading questions in teaching practice in a Support Classroom for Portuguese Language Learning (SAAPL, in Portuguese) $-6^{\text {th }}$ grade of a regular public school in the South-Central region of the state of Parana. Based upon the concepts discussed by Bakhtin Circle

* cristiane.mpa@gmail.com

** renilson@wnet.com.br

${ }^{1}$ Parte deste texto foi apresentado no IV Congresso Nacional de Linguagens em Interação: Múltiplos Olhares, em Maringá-PR, em 5 a 7 de junho de 2013. 
and the contributions from Applied Linguistics, the present work aimed to guide and follow up on one teacher's practice in a SAAPL classroom in his task of preparing after-reading questions. Data collection was perfomed before and after some theoretical and methodological interventions with the teacher, carried out in a collaborative manner, providing theoretical support and guided discussions on the concepts and stages of the reading process and their implications for the Portuguese language teaching and learning processes. The results indicate the need to provide the SAAPL teacher with theoretical and methodological support in relation to the reading process, as well to supervise and guide his/her practice during the preparation of reading questions in this particular context. KEYWORDS: reading questions, Support Classroom for Learning, continuing teacher education.

\section{Considerações iniciais}

Diversos estudiosos da Linguística Aplicada, como Terzi (1995), Solé (1998), Marcuschi (2001) e Menegassi (2010a; 2010b; 2010c; 2011), apontam que a pergunta utilizada pelo professor, em situação de ensino, determina a forma como o aluno posiciona-se frente ao texto, durante a leitura, influenciando na sua formação e no seu desenvolvimento como leitor. Desse modo, assim como as perguntas levam o aluno a uma gama variada de avanços nessa habilidade, tornando-os críticos que interagem com o texto que leem, podem também propiciar a formação de um leitor apático, que apenas cumpre a leitura a partir da direção dada, sem manifestaçôes de responsividade pertinentes.

Ao considerarmos esses pressupostos e tomarmos as proposições da pesquisa crítico-colaborativa, abordamos, neste artigo, a construção de perguntas de leitura na prática docente junto a alunos de uma Sala de Apoio à Aprendizagem de Língua Portuguesa (SAALP) - $6^{\circ}$ ano do Ensino Fundamental. Temos por objetivos: a) analisar as perguntas de leitura produzidas por um professor de SAALP; $b$ ) analisar as perguntas produzidas após o desenvolvimento de ações colaborativas junto ao professor; c) discutir que tipologia e ordenação de perguntas são mais adequadas para propiciar o desenvolvimento da competência leitora, especificamente do aluno da SAALP.

Para tanto, inicialmente, discutimos as noções conceituais bakhtinianas de linguagem que sustentam a pesquisa, vinculando-as à concepção dialógica de leitura e à produção de perguntas de leitura. Após, explicitamos a forma de coleta dos dados; apresentamos e discutimos as perguntas produzidas pelo professor; relatamos as açôes colaborativas desenvolvidas junto a ele, bem como verificamos os reflexos dessas ações na prática docente, na situação de produção de perguntas de leitura. 


\section{Revisão da Literatura}

\subsection{Dialogismo, leitura dialógica e processo da leitura}

Para compreendermos o dialogismo no Círculo de Bakhtin (BAKHTIN/VOLOCHINOV, 1926/1976; BAKHTIN/VOLOCHINOV, 1999; BAKHTIN, 2003), precisamos averiguar, primeiramente, de que forma essa teoria se posiciona frente às formulações linguístico-filosóficas do início do século XX para, então, abordarmos as diferentes dimensões que dão à linguagem um caráter essencialmente dialógico.

Os pressupostos dialógicos bakhtinianos são decorrentes das reflexões e críticas realizadas pelo Círculo a respeito de duas orientaçōes teóricas vigentes no início do século XX, denominadas por Bakhtin/Volochinov (1999) como subjetivismo individualista e objetivismo abstrato, as quais reduzem a linguagem, respectivamente, à enunciação monológica isolada e a um sistema abstrato de formas e, desse modo, impedem de se percebê-la na sua totalidade, na sua relação com as atuaçõoes humanas e com a vida. Assim, quanto à primeira orientação, Bakhtin/Volochinov contestam a ideia de que o fenômeno linguístico consiste em um ato significativo de criação individual, livre das influências e do controle do contexto, como também questionam, referindose à segunda orientação, a noção de que a língua é "um arco-íris imóvel” (1999, p.77) que permite aos locutores pronunciar e escutar, no dia a dia, meros itens de dicionário e não palavras carregadas de conteúdos e sentidos vivenciais. Os teóricos ressaltam categoricamente: "A língua vive e evolui historicamente na comunicação verbal concreta, não no sistema linguístico abstrato das formas da língua nem no psiquismo individual dos falantes" (BAKHTIN/ VOLOCHINOV, 1999, p.124, grifos dos autores).

Ao apreender a linguagem numa perspectiva global, o que conduz o dialogismo bakhtiniano a ser caracterizado como uma translinguística (CLARK; HOLQUIST, 2004), Bakhtin/Volochinov asseguram que a linguagem só pode ser compreendida na relação com os seus elementos constitutivos: a realidade socio-histórica, os participantes, o lugar, o espaço temporal, as intenções comunicativas, as diferentes materialidades (verbais, visuais, sonoras etc.), os gêneros discursivos, que são inerentes ao sentido de um discurso produzido numa circunstância comunicativa única e irrepetível. Por isso, o verdadeiro núcleo da língua, para Bakhtin/ Volochinov (1999), não é o ato de fala puramente individual e isolado nem o sistema de normas imutáveis, mas o diálogo, entendendo-o não como troca de turnos entre os 
participantes de uma conversa face a face, mas como as relações de forças sociais que atuam e condicionam a forma e as significações de toda a comunicação verbal, de qualquer manifestação que seja (BAKHTIN/ VOLOCHINOV, 1999; FARACO, 2003).

Nessa abordagem totalizante, o dialogismo possui múltiplas dimensões, estando todas firmemente ligadas no todo do enunciado, este que, na ótica bakhtiniana, remete para o ato concreto de uso da linguagem, a apresentação autêntica e objetiva da língua (BAKHTIN, 2003). Essas dimensões são discutidas ao longo das obras que compóem o Círculo e podem ser sistematizadas:

a) Todo enunciado constitui um diálogo com a própria situação extraverbal que o envolve. Isso porque, segundo Bakhtin e Volochinov, “(...) o discurso verbal é claramente não autossuficiente. Ele nasce de uma situação pragmática extraverbal e mantém a conexão mais próxima possível com esta situação. Além disso, tal discurso é diretamente vinculado à vida em si e não pode ser divorciado dela sem perder sua significação" (1926/1976, p.4). Desse modo, os elementos da situação pragmática extraverbal estão sempre entremeados no enunciado, unindo os participantes da atividade comunicativa como "co-participantes que conhecem, entendem e avaliam a situação de maneira igual” (BAKHTIN/VOLOCHINOV,1926/1976, p.5, grifos dos autores) e dando-lhe sustentação;

b) Todo enunciado se dirige para alguém. E é em função deste que a palavra toma forma: "Variará se se tratar de uma pessoa do mesmo grupo social ou não, se esta for inferior ou superior, se estiver ligado ao locutor por laços sociais mais ou menos estreitos (pai, mãe, marido, etc.)." (BAKHTIN/ VOLOCHINOV, 1999, p.112). Nesse sentido, não apenas a individualidade daquele a quem a palavra é dirigida tem uma função constitutiva, condicionante, do dizer, como também a posição social que o interlocutor evidencia no diálogo com o outro e a conjuntura na qual se encontram inseridos;

c) Todo enunciado procede de alguém. Considerando-se que, na abordagem bakhtiniana, o falante não executa apenas um ato fisiológico de materialização da palavra, mas pronuncia palavras-signos as quais são sempre submetidas aos critérios de avaliação ideológica (se é bom, plausível, válido etc.), “a própria realização deste signo social na enunciação concreta é inteiramente determinada pelas relações sociais" (BAKHTIN/ VOLOCHINOV, 1999, p.113). A individuação da palavra reflete, então, a inter-relação social; 
d) Todo enunciado orienta-se para o já-dito e, assim, "não passa de um elo da cadeia dos atos de fala” (BAKHTIN/ VOLOCHINOV, 1999, p.98). Apresentandose como um elo, não pode ser nem o primeiro nem o último, visto que já emerge como réplica a outros enunciados, prolongando enunciados que o antecederam;

e) Todo enunciado é produzido na expectativa de se obter contrapalavras; "conta com as reações ativas da compreensão, antecipa-as." (BAKHTIN/ VOLOCHINOV, 1999, p.98). Por essa razão, o enunciado não somente concretiza o novo elo da comunicação discursiva ao responder o já-dito, como também constitui antecipadamente o elo a ser estabelecido nas respostas potenciais. Ao contar com as contrapalavras, o falante/produtor não espera mera dublagem, que não traz consigo nada de novo e enriquecedor, mas leva em conta que o ouvinte/leitor apropria-se ativamente da "palavra alheia", soma a essa palavra as suas experiências individuais, convertendo-a em "palavra própria alheia", para então gerar um novo dizer, a "palavra própria”, pois esta é reelaborada, reacentuada, possuindo um caráter de novidade (BAKHTIN, 2003);

f) Todo enunciado é essencialmente polifônico, “(...) pois em cada palavra há vozes, vozes que podem ser infinitamente longínquas, anônimas, quase despersonalizadas (...), inapreensíveis, e vozes próximas que soam simultaneamente" (BAKHTIN, 2003, p.353). Nesse sentido, os "eus" que surgem nas práticas discursivas manifestam vozes de autoridade, submissão, resistência, conflito, repúdio, silêncio, entre diversas outras que circulam e interagem socialmente.

Podemos perceber que, perpassando essa multiplicidade de dimensões inerentes ao dialogismo, estão duas noções basilares que contribuem para a conceitualização de texto verbal: $1^{\text {a)}}$ discurso e conjuntura social são indissociáveis; $2^{a}$ ) os participantes da atividade comunicativa estão em constante e ininterrupta interação. Nessa direção, o texto, oral ou escrito, é pensado segundo a concepção bakhtiniana de enunciado, pois não se mostra indiferente à situação social (imediata e ampla) em que é produzido e está inserido, e às relaçôes entre quem fala e quem ouve; entre quem escreve e quem lê: "Os falantes no diálogo se constroem e constroem juntos o texto e seus sentidos” (BARROS, 1996, p.31).

Essas postulações concernentes à linguagem, assumidas pelo Círculo de Bakhtin, determinam a leitura não como um ato monológico, de mera identificação ou repetição, mas como atividade de co-enunciação (CURADO, 2010), como réplica (MENEGASSI, 2010c; ROJO, 2004; 2009), entendida 
como leitura dialógica. Curado relaciona a atividade leitora com a noção bakhtiniana de signo: "O contexto confere mobilidade ao signo (por isso ele é dialético, vivo, variável, flexível) (...) Enquanto signo, a palavra implica uma concepção de leitura como atividade, ação entre interlocutores, dialogicidade" (CURADO, 2010, p.146), como acontecimento.

Numa ampliação às discussões acerca dessas relaçôes entre leitura e signo, estabelecemos a leitura como um ato de construir refraçôes da realidade. De acordo com a teoria bakhtiniana, com os signos não apenas refletimos ou fazemos um decalque do mundo, mas também refratamos o mundo, ou seja, produzimos diversas interpretações desse mundo a partir da diversidade de experiências históricas e socioculturais em que estamos inseridos (BAKHTIN/ VOLOCHINOV, 1999), uma das características da leitura réplica, dialógica. Explicando o conceito de refração, Faraco afirma que, para o Círculo, refratar é condição intrínseca do significar, visto que

(...) as significações não estão dadas no signo em si, nem estão garantidas por um sistema semântico abstrato, único e atemporal, nem pela referência a um mundo dado uniforme e transparentemente, mas são construídas na dinâmica da história e estão marcadas pela diversidade de experiências dos grupos humanos, com suas inúmeras contradiçôes e confrontos de valorações e interesses sociais. (FARACO, 2003, p.50).

Assim, ao ler, o leitor não apenas espelha ou descreve o mundo que se inscreve nas palavras, mas realiza reflexões, constrói refrações acerca do modo como se revelam nos textos a multiplicidade e as contradições oriundas das experiências históricas das sociedades humanas.

Rojo (2004; 2009) e Menegassi (2010c), também recuperando os fundamentos do dialogismo do Círculo de Bakhtin, concebem a leitura como réplica, ou seja, como uma ação de colocar-se em frente aos textos e discursos em voga na sociedade, de discutir com os textos, respondendo e avaliando posições e ideologias que constituem seus sentidos; enfim, como uma ação de "trazer o texto para a vida e colocá-lo em relação com ela" (ROJO, 2004, p.1), de dialogar com ele. Desse modo, na visão de Menegassi (2010c), o leitor é aquele que dialoga com o texto lido, posiciona-se como respondente ativo e crítico frente ao material trabalhado, permitindo a produção de sentidos próprios, que se revelam por meio de palavras próprias, direcionando-se, então, à construção do pensamento autônomo. 
Para esse autor, é preciso que o docente auxilie o aluno a construir-se progressivamente como leitor ativo, criativo, e isso exige o conhecimento bem fundamentado acerca das etapas que compóem o processo leitor. Essas etapas, quando trabalhadas de forma adequada em sala de aula, levam o aluno a construir-se paulatinamente como um leitor mais autônomo, mais crítico, capaz de produzir palavras próprias.

Assim sendo, para que o leitor construa a leitura réplica, inicialmente ele precisa conseguir recuperar e produzir significados no processamento da decodificação - primeira etapa do processo da leitura, reconhecendo o código escrito e o associando ao significado pretendido no texto. Essa etapa é basilar para que o leitor atinja a compreensão - segunda etapa do processo - na qual o leitor, respondente crítico, não apenas extrai conteúdos, mas também produz inferências, isto é, mergulha no texto para estabelecer relações entre as informações do texto e para articular os dados textuais com os seus conhecimentos prévios, as suas experiências individuais. Ao chegar a esse nível, o leitor está em condições de constituir "palavras próprias", o que o conduz à terceira etapa do processo: a interpretação - "a etapa da utilização da capacidade crítica do leitor, o momento em que analisa, reflete e julga as informações que lê" (MENEGASSI, 2010c, p.50), suscitando, desse modo, um novo texto, fruto da manifestação de leitura realizada por meio de informações diferentes do texto original. Nessa situação, o leitor vai além das linhas, para questionar o que foi lido e compreendido, debater as visões e ideias do mundo a partir da interação com o autor, via texto, constituindo a noção de leitura réplica (ROJO, 2004; 2009; MENEGASSI, 2010c). A última etapa do processo da leitura, descrito por Menegassi (2010c), é a retenção, que se destina a armazenar as informações mais importantes na memória do leitor. O leitor pode guardar na memória os dados textuais, sem analisá-los ou julgá-los, como também pode reter as informaçôes que resultam da análise e julgamento realizado a respeito do texto lido. É nesse caso que o leitor altera seu ponto de vista sobre o tema e gera um novo dizer, visto que este já possui uma natureza criativa e autônoma.

Para promover um leitor que atua em refração, oferece contrapalavras, constrói réplicas, consideramos imprescindível problematizar as modalidades, a sequenciação e ordenação de perguntas de leitura que se trabalha em sala de aula, pois os modelos de perguntas oferecidos determinam os comportamentos e as atitudes do leitor frente ao texto. Discutiremos esses aspectos na próxima seção. 


\subsection{Perguntas de leitura: exercício ou atividade?}

No cotidiano da sala de aula de língua materna, os termos "exercício" e "atividade" são bastante recorrentes e, na maioria das vezes, são empregados como se fossem sinônimos. Ponderamos, no entanto, que cada um desses termos recobre noções diferenciadas de linguagem, de língua e do processo de ensino e de aprendizagem. Para Cerqueira (2010), a adoção de qualquer um dos dois conceitos traz implicações também no modo de se conceber a educação como um todo. Nesse sentido, de acordo com a autora, a noção de atividade extrapola "a visão imediatista da sala de aula, refletindo-se na formação dos sujeitos, de uma forma mais ampla”, enquanto que o exercício constitui-se como um instrumento que serve para verificar o grau de compreensão do aluno acerca de um tópico específico do conteúdo programático, "não havendo, necessariamente, um comprometimento com a formação para além do espaço da sala de aula, mas a predominância do treinamento do que é ensinado" (CERQUEIRA, 2010, p.132).

Ao atrelar esses conceitos às concepçóes de língua e de ensino de língua, Cerqueira (2010) explica que a noção de exercício coaduna-se com os pressupostos teórico-metodológicos da gramática tradicional e da abordagem estruturalista. Quando se filia aos primeiros, o exercício está a serviço imediato do ensino da gramática normativa, contemplando suas categorizações, classificações e definições de termos e de classes de palavras. Ao vincular-se ao Estruturalismo, ou ao objetivismo abstrato, na acepção de Bakhtin/ Volochinov (1999), o exercício fundamenta-se na concepção behaviorista de aprendizagem, realçando, portanto, a formação de hábitos automáticos por parte do aprendiz, através de tarefas em que o aluno é levado a treinar uma determinada estrutura com base em um modelo, sem a reflexão necessária ao desenvolvimento do conhecimento ensinado. Por exemplo: "Transforme as frases de acordo com o modelo: Assisti a cenas que me fascinaram. Resposta: Assisti a cenas fascinantes." Nos dois casos, as tarefas escolares aparecem totalmente dissociadas dos diferentes usos sociais da linguagem e convertidas em momento de treino para avaliação puramente.

Em se tratando de ensino de leitura, quando se tem como pressuposto a ideia de exercício, concebe-se o leitor como aquele que domina a estrutura silábica e sabe decodificar, ou seja, passar do código escrito para o oral, o que corresponde a "uma teoria completamente falsa da compreensão", empregando a ideia de Bakhtin/Volochinov (1999, p.99), vinculada à visão de língua como um sistema de normas linguísticas, estável e imutável, dissociada da 
enunciação, somente estudada a partir do reconhecimento de objetos-sinais (ÂNGELO; MENEGASSI, 2011). Nessa perspectiva, o trabalho com o texto segue quase sempre um mesmo ritual: solicita-se ao aluno a leitura do material e, logo após, oferece-lhe um conjunto de perguntas a respeito do que foi lido, as quais geralmente dispensam-no de envolver-se com o significado, pois se atêm somente a aspectos formais do texto ou, então, limitam todo o trabalho de compreensão à "copiação" de informações objetivas e superficiais, a partir de questionamentos como: "Qual é o título do texto?"; "Quantas estrofes têm o poema?"; "Quem são os personagens do texto?", o que corresponde à ideia de leitura como não mais que reflexo, um decalque do material textual.

Já o conceito de atividade orienta-se pela concepção dialógica de linguagem, proposta pelo Círculo de Bakhtin, visto que a abordagem remete para o enunciado, enquanto unidade real e concreta da comunicação discursiva, que não se esgota nos limites da dimensão linguística, mas sempre se encontra vinculado às condições da situação de interação social e a outros enunciados, porque é sempre resposta a outros enunciados, ao mesmo tempo está sempre a "espera" de uma resposta, orientando-se sempre para o outro.

$\mathrm{Na}$ situação de leitura, o conceito de atividade pressupõe um leitor que atua em refração, isto é, que não se mantém apático diante do texto, mas que participa ativamente de toda a prática interativa ao ocupar uma posição responsiva e expandir o processo comunicativo. Desse modo, as perguntas de leitura conduzem o aluno-leitor a realizar um trabalho de interação com o texto, a raciocinar sobre o que está lendo, a articular o tema do texto à sua vida pessoal e a criar uma interpretação textual própria.

Menegassi (2010b), numa abordagem muito próxima à ideia de atividade, defende que as perguntas de leitura precisam auxiliar o aluno-leitor na produção de sentidos do texto trabalhado em sala de aula. Nesse âmbito, o autor diferencia as perguntas que promovem a formação do leitor das que suscitam o seu desenvolvimento. Aquelas orientam leituras que não ultrapassam a superfície textual, isto é, que determinam respostas de pareamento de informaçóes com o texto trabalhado; estas, partindo do princípio de que a formação já foi estabelecida, encaminham para respostas que conduzem o aluno-leitor à produção de sentidos diversos ao tema abordado no texto, necessariamente relacionando-o a sua vida, de modo que a leitura de fato lhe faça sentido.

Assim, para promover a formação e o desenvolvimento do leitor, Menegassi (2010b), recuperando as etapas do processo de leitura 
(MENEGASSI, 2010c) e as discussões de Solé (1998), propõe que sejam trabalhados três tipos de perguntas: perguntas de resposta textual, perguntas de resposta inferencial, perguntas de resposta interpretativa. As primeiras caracterizam-se como perguntas cujas respostas são retiradas literalmente do texto, no entanto, não são perguntas de pareamento, em que o aluno toma as palavras que aparecem no comando, localiza-as no texto e copia o trecho seguinte, considerando-o como a resposta, mas que "exigem do aluno a compreensão do seu enunciado e um trabalho efetivo de interação com o texto, para que a resposta seja produzida” (MENEGASSI, 2010b, p.179). As perguntas de resposta inferencial são aquelas que determinam que o aluno-leitor estabeleça relações entre o texto e as informações que possui em seu conhecimento prévio, produzindo algum tipo de inferência. Nesse caso, “a resposta não está no texto; está na relação do texto com as inferências produzidas pelo leitor, que deve construir uma resposta a partir da relação 'pensar sobre o texto e buscar resposta fora dele" (MENEGASSI, 2010b, p.180). Já as perguntas de resposta interpretativa solicitam que o leitor elabore uma resposta pessoal. Elas partem do texto, "porém, as respostas não podem ser deduzidas exclusivamente dele, exigindo a intervenção do conhecimento prévio e da opinião do leitor, numa nítida produção de sentidos a partir dos significados do texto" (MENEGASSI, 2010b, p.181).

Para MENEGASSI (2010b), essas três classificações necessitam ser trabalhadas em sala de aula, visto que englobam todas as etapas do processamento da leitura. Além disso, segundo o autor, é preciso também levar em consideração o modo como as perguntas são ordenadas: primeiramente, oferecer perguntas de resposta textual para que o aluno aprenda a trabalhar com o texto; após, apresentar as perguntas de resposta inferencial com a finalidade de que o aluno estabeleça relaçõos entre o texto e as informaçôes que possui em seu conhecimento prévio; por último, propiciar perguntas de resposta interpretativa com o intuito de que o aluno chegue à possibilidade de produzir sentidos próprios ao tema discutido. Portanto, conforme aponta MENEGASSI (2010b, 2011) e corroborado por pesquisa de Rodrigues (2013), as perguntas precisam atender uma ordem crescente de dificuldades, de modo a conduzir o leitor a uma progressiva reflexão sobre o texto com o qual está interagindo.

A partir da discussão dos pressupostos dialógicos da linguagem e da leitura e das características das perguntas de leitura, passamos a relatar e discutir o trabalho docente com esses enunciados no contexto da SAALP. 


\section{As perguntas de leitura na SAALP}

Tomamos como corpus as perguntas de leitura produzidas por um professor de SAALP - $6^{\circ}$ ano do Ensino Fundamental, na região CentroSul do Estado do Paraná. Ressaltamos que a Sala de Apoio à Aprendizagem é um programa instituído, em 2004, pela Secretaria Estadual de Educação do Paraná - SEED com o objetivo de atender às dificuldades de aprendizagem das crianças da segunda etapa do Ensino Fundamental. ${ }^{2}$ Esses alunos frequentam aulas de Língua Portuguesa e/ou Matemática no contraturno, participando de atividades que visam à superação das dificuldades referentes aos conteúdos dessas disciplinas, até mesmo de seus comportamentos leitores. Selecionamos a SAALP em virtude de que as ações educativas nesse contexto incidem prioritariamente na leitura e na escrita, sendo as perguntas de leitura uma estratégia significativa para propiciar a formação e o desenvolvimento do leitor.

A produção de perguntas deu-se em dois momentos: um inicial, antes do desenvolvimento de ações colaborativas junto ao professor; outro final, após as ações colaborativas. Buscamos analisar a tipologia de perguntas oferecida aos alunos e o modo como são ordenadas, sequenciadas e formuladas.

\subsection{As perguntas de leitura antes das ações colaborativas}

Apresentamos para discussão dois questionários de leitura, um referente à história em quadrinhos "Chico Bento em 'A verdade tem pernas compridas", reproduzido no Bloco 1, e outro referente à fábula "O rato do campo e o rato da cidade", no Bloco 2. Esses questionários foram aplicados aos alunos da SAALP no início do ano letivo, sem qualquer interferência teóricometodológica da pesquisa, como controle dos dados.

\footnotetext{
${ }^{2}$ Fonte: <http://www.gestaoescolar.diaadia.pr.gov.br/modules/conteudo/conteudo.
} php? conteudo=28>. Acesso em: 13 out. 2013. 


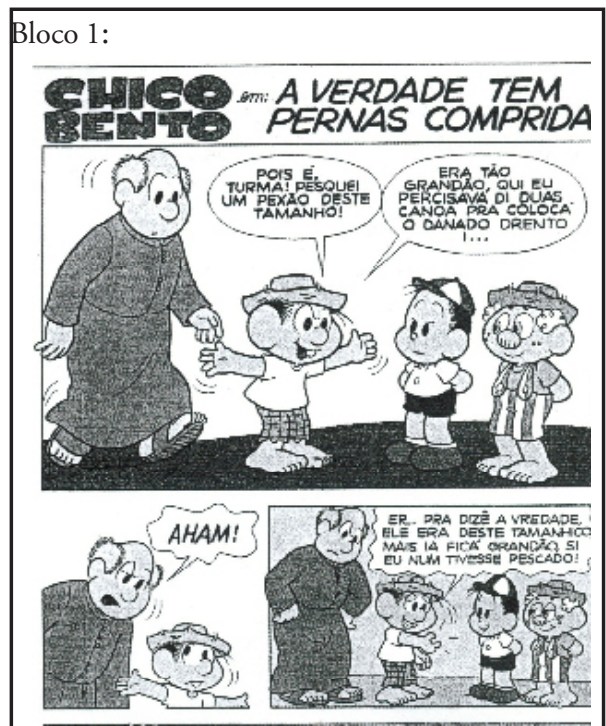

(Mauricio de Sousa - não foram apresentados aos alunos outros dados referenciais do texto)

a) No texto de "Chico Bento" encontramos o título "A verdade tem pernas compridas". Você conhece outro ditado popular que contraria essa frase?

b) Quem conta mentiras sempre acaba descoberto e pagando pelos seus erros. Você acha que devemos sempre falar a verdade, assim como fez Chico Bento?

c) Qual a classe de profissionais que você considera mais mentirosa? Por quê?

d) A fábula sempre traz uma moral (conselho). Você lembrou-se de outro texto que trata do mesmo tema?
Bloco 2:

O rato do campo e o rato da cidade

Certa vez, o rato do campo convidou seu amigo que morava na cidade para ir visitá-lo.

No dia combinado, o rato da cidade partiu rumo ao campo, alegre e entusiasmado para experimentar as novidades. Porém, na hora do almoço, ele ficou decepcionado com os pratos servidos: grãos de lentilha sem sal e algumas raízes com gosto de terra fresquinha. Inconformado, exclamou:

- Coitado de você, meu amigo! Não é à toa que é tão magricela! Venha morar comigo na cidade que, juntos, iremos comer as mais finas iguarias deste país!

E lá se foram os dois ratinhos para a cidade. $(\ldots)$

MATTOS, Ângela. O rato do campo e o rato da cidade. Texto não publicado, Curitiba, 2006.

Obs.: Os alunos receberam os textos na íntegra. Reproduzimos apenas uma parte de cada um deles em virtude do espaço.

a) $\mathrm{Na}$ fábula "O rato do campo e o rato da cidade", o rato da cidade tem mais dificuldade para conseguir comida. Você concorda com essa ideia?

b) Na história, o rato da cidade julga a alimentação do campo muito fraca (ruim, insuficiente). Você concorda?

c) Você concorda que existe uma dependência entre o campo e a cidade?

d) Faça uma lista de coisas que encontramos no campo e na cidade. 
Podemos constatar que todo esse conjunto de questôes configura-se como perguntas de elaboração pessoal (SOLÉ, 1998), sendo que a 1a, 1d e $2 \mathrm{~d}$ procuram despertar o conhecimento prévio do leitor, fazendo-o buscar, em sua bagagem cognitiva, a resposta para as perguntas, sem manifestação de opinião ou crítica, enquanto que as demais, 1b, 1c, 2a, 2b e 2c, solicitam que o aluno emita um parecer, uma avaliação a respeito do texto ou da sociedade.

Percebemos que as perguntas "No texto de 'Chico Bento' encontramoso titulo 'A verdade tem pernas compridas'. Você conhece outro ditado popular que contraria essa frase?" " "Faça uma lista de coisas que encontramos no campo e na cidade. "poderiam ser utilizadas antes da leitura, como atividade de pré-leitura (TAGLIEBER; PEREIRA, 1997), no intuito de acionar os conhecimentos a respeito do texto, estimulando o aluno a ter um comportamento mais ativo desde o início do processo. Empregadas como atividade de pós-leitura, podem ser respondidas sem que o aluno sequer tenha lido o material; consequentemente, não oferecem contribuição para que o aluno avalie as informações postas em circulação pelo texto.

Já a questão "A fábula sempre traz uma moral (conselho). Você se lembrou de outro texto que trata do mesmo tema?" apresenta uma organização que traz dificuldades ao aluno de SAALP. A pergunta refere-se a uma fábula, no entanto, o texto estudado, "Chico Bento em: A verdade tem pernas compridas", trata-se de uma história em quadrinhos. Além disso, exige-se atenção para dois aspectos diferentes: a primeira parte do comando apresenta uma característica intrínseca da fábula, a presença da moral; a segunda parte solicita que o aluno recorra a sua memória para lembrar-se de outro texto que trate da mesma temática abordada na história lida. Ainda, para que o aluno responda à pergunta é preciso que, primeiramente, ele identifique o tema do texto, questão que não foi abordada nas perguntas anteriores, sendo que, sozinho, o aluno ainda em processo de formação como leitor certamente não consegue dar conta.

Quanto às questôes que solicitam um posicionamento do leitor, também observamos alguns problemas. A pergunta "Quem conta mentiras sempre acaba descoberto e pagando pelos seus erros. Você acha que devemos sempre falar a verdade, assim como fez Chico Bento?" conduz à interpretação textual desejada pelo professor, ao induzir o aluno a responder "sim", que sempre devemos falar a verdade, portanto, cerceando-lhe a criticidade e a produção de contrapalavras. O mesmo ocorre em "Na fábula ' $O$ rato do campo e o rato da cidade, o rato da cidade tem mais dificuldade para conseguir comida. Você concorda com essa ideia?" " "Você concorda que existe uma dependência entre o 
campo e a cidade?", em que o professor já aponta no comando o que espera como resposta, ceifando a capacidade criadora dos alunos.

A pergunta "Qual a classe de profissionais que você considera mais mentirosa? Por quê?? também apresenta uma formulação imprecisa. Além de incentivar o aluno a generalizar, atribuindo uma característica negativa a toda uma classe de profissionais, seguindo o senso comum, e não a comportamento de algumas pessoas de determinadas classes, a pergunta pode ser respondida sem a necessidade de compreensão textual, que, conforme estudos do processo da leitura (MENEGASSI, 2010c), é basilar para o avanço a níveis mais profundos da leitura, que propiciam o desenvolvimento do leitor.

Consideramos mais pertinente para o processo interpretativo apenas a pergunta "Na história, o rato da cidade julga a alimentação do campo muito fraca (ruim, insuficiente). Você concorda?", a qual auxilia o aluno a avaliar uma determinada informação presente no texto. No entanto, em virtude de as demais perguntas do bloco negligenciarem a interação entre o aluno e o texto, pouco contribui para que o aluno de fato construa sentidos para o texto.

Em síntese, a análise das questões apresentadas permitiu levantar alguns aspectos:

- o professor, ao elaborar as perguntas, não considera as etapas do processamento da leitura;

- privilegia questões interpretativas, de elaboração pessoal, em detrimento das perguntas de resposta textual e de resposta inferencial;

- ao ignorar as perguntas de resposta textual e de resposta inferencial, parte do princípio de que o texto já foi lido e entendido e passa diretamente à interpretação, sem preocupação em verificar se houve compreensão;

- desconsidera um pressuposto básico da leitura crítica: a interação com o texto, embora as perguntas tragam na sua formulação expressões que sugerem criticidade, como "você acha", "você concorda";

- além disso, formula alguns comandos de modo a direcionar a interpretação do texto, não propiciando o desenvolvimento da criatividade e do pensar críticoreflexivo do aluno;

- uma vez que negligencia o texto, elabora exercícios, destinados mais a ocupar o tempo do aprendiz, e não atividades (CERQUEIRA, 2010), as quais implicam uma efetiva interação do leitor com o texto. 


\subsection{Ações colaborativas junto ao professor de SAALP}

Definimos nossa pesquisa como crítico-colaborativa (MAGALHÃES, 2002), visto que assumimos a colaboração como elemento fundamental ao processo de intervenção para desvendar sentidos da realidade. Nessa pesquisa, “(...) os facilitadores externos entram em relação colaborativa com os práticos e ajudam a articular suas próprias preocupaçōes, a planejar as ações estratégicas para mudanças, a detectar os problemas e os efeitos das mudanças, bem como a refletir sobre sua validade e consequências" (JESUS; ALMEIDA; SOBRINHO, 2005, p.4).

Para o desenvolvimento das açôes colaborativas, utilizamos diversos instrumentos, sendo os principais: os textos teórico-metodológicos, os roteiros de discussão e as sessóes reflexivas. Para a abordagem dos aspectos concernentes ao processo da leitura e às perguntas de leitura, solicitamos ao professor a leitura de três textos:

- MENEGASSI. O leitor e o processo de leitura. In: GRECO, E. A.; GUIMARÃES, T. B. (Org.) Leitura: aspectos teóricos e práticos. Maringá: Eduem, 2010c. p.35-59;

- MENEGASSI. As perguntas na avaliação de leitura. In: MENEGASSI (Org.) Leitura e ensino. 2.ed. Maringá: Eduem, 2010a. p.96-100 (Capítulo: Avaliação de leitura);

- MENEGASSI. Perguntas de leitura. In: MENEGASSI (Org.) Leitura e ensino. 2.ed. Maringá: Eduem, 2010b. p.167-189.

Juntamente com uma cópia desses textos, entregamos um roteiro de discussão que continha questôes orientadoras da leitura e atividades que instigavam o professor a refletir acerca de sua prática em SAALP. Esses materiais foram tomados como objetos de discussão nas sessões reflexivas que ocorreram na própria escola, no momento da hora-atividade do professor. Nessas sessōes, pudemos, em conjunto com o professor: a) discutir as diferenças entre os processos de formação e desenvolvimento do leitor; b) levantar as características do leitor crítico; c) estudar as etapas do processo de leitura: decodificação, compreensão, interpretação e retenção; d) levantar as características que devem apresentar as perguntas de leitura; e) avaliar e classificar as perguntas de leitura sugeridas para o trabalho em SAALP; f) produzir perguntas pertinentes para esse contexto de ensino.

Apresentamos e comentamos uma das atividades presentes em um dos roteiros de discussão disponibilizado ao professor. A atividade solicitava que o professor, a partir da leitura do texto "O leitor e o processo de leitura" (MENEGASSI, 2010c), avaliasse e classificasse as perguntas de leitura sugeridas para o trabalho em SAALP com um texto do gênero relato histórico: 
De acordo com Menegassi, por ser um processo, a leitura se desenvolve em etapas, sendo elas: a decodificação, a compreensão, a interpretação e a retenção. Reflita sobre as etapas da compreensão e interpretação, a partir das perguntas de leitura elaboradas para o texto "Escova de dentes: como fazíamos sem":

\section{Escova de dentes: como fazíamos sem}

Livia Lombardo $(01 / 11 / 2005)$

A primeira escova de que se tem notícia foi encontrada numa tumba de 5 mil anos. $\mathrm{Na}$ verdade, era um pequeno ramo de planta que foi desfiado até as fibras aparecerem - elas eram esfregadas nos dentes para limpá-los.

O mau hálito deve ter incomodado os povos antigos. Tanto que outras alternativas para auxiliar na higiene bucal foram criadas com o passar dos anos. Além dos dedos, de folhas e de gravetos, pequenas varetas com a ponta amassada também eram utilizadas para limpar os dentes. Diocles de Caristo, um médico grego do século 4 a.C., deixou escrito um documento em que recomendava a seus clientes que todas as manhãs colocassem uma fina camada de hortelã pulverizada nos dentes e nas gengivas e a esfregasse com os dedos para remover restos de alimentos. Já os romanos limpavam seus dentes com um pó bem diferente - os ingredientes eram cinzas de ossos e dentes de animais, ervas e areia. A importância da escovação já era tão grande que os aristocratas tinham escravos apenas para limpar seus dentes.

Na Idade Média, as escovas ainda não haviam evoluído muito, mas as pastas de dentes já tinham melhorado bastante. Nessa época, eram preparadas à base de ervas aromáticas, como a sálvia. Mas, para eliminar o mau hálito, eram recomendados bochechos com urina.

A escova de dentes de cerdas só foi inventada em 1498, pelos chineses. Porém, além do fato de serem muito caras - e, por isso, famílias inteiras terem que dividir uma peça -, eram feitas de pêlos de porcos atados a pedaços de bambus ou ossos. Com a umidade, os pêlos mofavam e enchiam a boca de fungos.

O problema só seria resolvido em 1938, nos Estados Unidos, com o surgimento de cerdas de náilon. Na Segunda Guerra Mundial, os soldados americanos eram obrigados a usar a escova de dentes. De lá para cá, ela só foi se aperfeiçoando. Uma pesquisa feita em 2003 nos Estados Unidos pelo Instituto de Tecnologia de Massachusetts surpreendeu pelo resultado: para os americanos, a escova de dentes é a invenção mais importante da história da humanidade.

Aventuras na História. Superinteressante online. Guia do estudante. Disponível em: http://guiadoestudante.abril.com.br/estudar/historia/escova-dentes-como-faziamossem-434363.shtml

\section{Questôes propostas:}

1- Antes do surgimento da escova de dentes de cerdas, de que forma os povos antigos (egípcios, gregos e romanos) realizavam a higiene bucal?

2- As primeiras escovas de dentes que surgiram, feitas de cerdas de pêlos de porcos, eram adequadas para o uso no dia a dia?

3- Por que os soldados americanos eram obrigados a usar a escova de dentes?

4- Você concorda com o resultado da pesquisa que apontou a escova de dentes como a invenção mais importante da história da humanidade?

5- Por que é importante cuidar dos dentes?

6- Que recursos você considera importantes na realização da higiene bucal? 
Constatamos que a questão 1 corresponde à etapa da compreensão literal; a questão 2, à etapa da compreensão textual; a questão 3 refere-se à compreensão extratextual e as questões 4,5 e 6 dizem respeito à etapa da interpretação. As modalidades e a sequenciação das perguntas refletem, então, as etapas do processo de leitura, explicitadas por Menegassi (2010c), propiciando ao leitor um processo de amadurecimento e de transformação. Salientamos que, apenas com a leitura do texto teórico, o professor dificilmente conseguiria aprender a formular perguntas que levem em consideração o processamento da leitura; por isso a importância de, no processo de formação continuada, fornecer-lhe modelos que o orientem no processo de construção das perguntas.

Selecionamos, também, um episódio de interação com o professor durante uma das sessões reflexivas, gravadas em áudio. $\mathrm{O}$ diálogo referiu-se ao texto "Perguntas na avaliação de leitura" (MENEGASSI, 2010a) e, na ocasião, objetivávamos possibilitar queo professor construísse conhecimento sobre as modalidades de perguntas a serem trabalhadas em sala de aula, clarificando e ampliando as reflexões propiciadas pelo texto e pelo roteiro de discussão acerca do processo da leitura. Para tanto, o professor leu o texto antecipadamente, tendo como guia o roteiro composto de questôes que indagavam a respeito das características que devem apresentar as perguntas de leitura trabalhadas pelo professor:

\section{Episódio}

Pesq. - Quanto a essa primeira questão... que características devem apresentar as perguntas de leitura trabalhadas pelo professor em sala de aula?

Prof. - Pelo que eu percebi seriam as questōes que ultrapassem a questão de decodificação, do pareamento... e que chegue à questão da compreensão e da interpretação... diferente das que o livro apresenta na maioria das vezes... as perguntas que os livros trazem são falhas... falhas no sentido de não atingir a leitura crítica...

Pesq. - Exato...

Prof. - Aqui no texto fala de quatro tipos de perguntas: perguntas que buscam respostas diretas do texto, perguntas que exigem inferência, aquelas que vão além do texto... perguntas de reflexão e perguntas relacionadas à vida do leitor...

Pesq. - E quando o professor faz esse processo leva o aluno ao desenvolvimento... o aluno vai progressivamente ampliando a sua capacidade 
de leitura...

Prof. - Diz ali pra frente que se o professor se preocupar em elaborar essas questóes seguindo essa tipologia ele vai estar mais preparado para ser um leitor crítico... desenvolver o leitor...

Pesq. - Se fosse preciso você conceituar ou explicar inferência... como você conceituaria?

Prof. - Acho que são aquelas perguntas que não vão direto para o texto... exigem um pouco mais de compreensão do texto... que já fazem o aluno pensar...

Pesq. - Sim... mas veja que a pergunta de interpretação também faz o aluno pensar...

Prof. - Então o que seria inferência?

Pesq. - Podemos dizer assim que é aquilo que é deduzido pelo leitor... a inferência não está no texto explicitamente... nem totalmente fora do texto... mas na ponte que liga o texto com o leitor... por exemplo, essa pergunta 'Por que os soldados americanos eram obrigados a usar a escova de dentes?' é uma pergunta de resposta inferencial porque o aluno precisa deduzir... inferir a partir da leitura de todo o texto...

Prof. - Sim... a resposta não tá aí clara no texto...o aluno precisa levar para o texto o que ele sabe...

Notamos que a leitura do texto teórico e as discussões possibilitaram ao professor a percepção das etapas do processo da leitura "(...) que ultrapassem a questão de decodificação, do pareamento... e que chegue à questão da compreensão e da interpretação (...)", como também das modalidades de perguntas de leitura: “(...) perguntas que buscam respostas diretas do texto, perguntas que exigem inferência, aquelas que vão além do texto, né... perguntas de reflexão e perguntas relacionadas à vida do leitor...". Baseando-se no material teórico, o professor destaca ainda a necessidade de se levar em conta essas modalidades com intuito de propiciar o desenvolvimento do leitor: “(..) se o professor se preocupar em elaborar essas questóes seguindo essa tipologia ele vai estar mais preparado para ser um leitor crítico né..., desenvolver o leitor...". Pela leitura e discussão, o professor percebeu também que as perguntas de interpretação podem ter focos diferentes, requisitando reflexão-perguntas quelevem o leitor a refletir sobre o tema do texto a partir de experiências de sua vida, criando uma interpretação textual (MENEGASSI, 2010a) - e relação com a vida do leitor - perguntas que relacionam o tema do texto com a vida do leitor (MENEGASSI, 2010a). 
Diante de um comentário vago tecido pelo professor, como, por exemplo, quando ele conceitua perguntas de inferência como “...aquelas que vão além do texto" e depois como "aquelas perguntas que não vão direto para o texto... exigem um pouco mais de compreensão do texto...que já fazem o aluno pensar...", instigamos o professor a refletir sobre esse conceito, colocando-o em dúvida: "...mas veja que a pergunta de interpretação também faz o aluno pensar...", o que leva o professor a questionar "então o que seria inferência?" Além de expor o conceito ao professor, ao final do episódio, apresentamos um exemplo de pergunta de inferência, contribuindo para que ele reformule o conceito exposto no início da interação: “... a resposta não tá aí clara no texto, né...o aluno precisa levar para o texto o que ele sabe...", ainda que de modo pouco aprofundado, já que não demonstramos, a partir da pergunta apresentada como exemplo, "Por que os soldados americanos eram obrigados a usar a escova de dentes?", como a resposta inferencial poderia ser produzida, o que auxiliaria o professor a perceber que a inferência não é meramente coletada da superfície textual nem adivinhada pelo leitor, mas construída nas relações entre texto e conhecimentos prévios do leitor.

Esses exemplos demonstram que as ações colaborativas buscaram propiciar ao professor os pressupostos básicos do processo de leitura que se mostraram ausentes anteriormente às intervenções teórico-metodológicas. Verificaremos, na próxima seção, de que modo esses pressupostos foram assimilados pelo professor e refletiram no processo de elaboração das perguntas de leitura.

\subsection{As perguntas de leitura após as ações colaborativas}

Posteriormente às leituras e às sessões reflexivas, o professor produziu perguntas de leitura para aplicação na SAALP. Para tanto, selecionou o texto "O velho burrinho", de Pedro Bandeira, e elaborou nove perguntas, separandoas em três grupos, sendo que o primeiro orientava que o aluno respondesse às questóes, com base nas informaçóes do texto; o segundo requisitava que se expusessem opiniōes a respeito das ocorrências na fábula; o terceiro objetivava que se relacionassem os acontecimentos do texto com a vida em sociedade. Acreditamos que essa divisão em blocos mostra-se positiva para o contexto da SAALP, pois evidencia ao aluno o que se espera do leitor, ou seja, que ele trabalhe com o texto, apresente um ponto de vista a respeito do que foi lido e estabeleça relações entre o texto e o meio circundante. 


\section{O velho burrinho}

Certa vez, uns homens tinham de fazer uma longa viagem e havia muita carga para ser levada pelos burros. Resolveram, então, deixar que cada burro escolhesse o que queria carregar. O mais velho dos burros, que foi o primeiro a escolher, decidiu carregar o balaio maior, o mais pesado de todos, aquele que levava a comida dos homens. Os outros burros caíram na risada e disseram:

- Mas que burro! Quanto mais velho, mais burro...

E lá se foi o burrinho velho com todo aquele peso às costas e, ainda por cima, ouvindo a gozação dos companheiros.

Mas, à medida que a viagem seguia, a cada parada os homens serviam-se da comida do balaio do velho burro. Assim, em poucos dias, andava ele muito feliz e folgado, com seu balaio quase vazio. Enquanto isso, os outros burros ainda suavam com o peso de suas cargas, que não tinham diminuído nem um pouquinho!

Pedro Bandeira

Com base nas informações do texto, responda as questôes a seguir:
a) Quem ajudou os homens no trabalho?
b) Quem foi o primeiro a escolher a carga para a viagem?
c) Que tipo de carga o burro mais velho decidiu levar?
d) Por que os burros mais novos riram do burro mais velho?
e) Explique o que aconteceu com a carga do burro mais velho durante a viagem.
f) Por que a carga dos burros mais novos não diminuiu durante a viagem?

Agora, as respostas que você vai escrever são pessoais, ou seja, dependem de seu entendimento e interpretação do texto (suas opiniōes):

g) Levando em conta os acontecimentos do texto, o que você pensa a respeito do comentário feito pelos burrinhos mais novos: "Mas que burro! Quanto mais velho, mais burro..."?

h) Na sua opinião, a opção do burro mais velho foi errada?

Na questão a seguir, você vai relacionar os acontecimentos do texto com a vida em sociedade:

i) No texto, os burros mais novos debocham, fazem gozação do burro mais velho. Esse tipo de atitude acontece em sua escola ou sala de aula?

No primeiro grupo de questôes, podemos constatar duas tipologias de perguntas: perguntas cujas respostas acham-se centradas exclusivamente no texto $(a, b, c)$ e perguntas cujas respostas exigem alguma inferência (d, e, f). No caso das primeiras, que na terminologia de Menegassi (2010b) podem ser denominadas como perguntas de resposta textual, exige-se que o leitor atente para os dados presentes na superfície do texto, reconhecendo os símbolos escritos e ligando-os com um significado. Assim, o aluno é conduzido a perceber que: a) os burros ajudaram os homens no trabalho; b) o burro mais velho foi o primeiro a escolher a carga para a viagem; c) o burro mais velho decidiu levar o balaio maior, mais pesado, que carregava a comida dos 
homens. Tais informações, coletadas literal e diretamente no texto, auxiliam, portanto, o aluno a realizar a primeira etapa da leitura: a decodificação aliada à compreensão.

Para responder as perguntas (d), (e) e (f), o aluno precisa construir inferência, adentrando mais no nível da compreensão. Em "Por que os burros mais novos riram do burro mais velho?", o aluno precisa realizar aquilo que Vidal-Abarca e Rico (2003) chamam “inferências de ligação textual”, isto é, o leitor necessita fazer conexões entre ideias sucessivas ou muito próximas no texto. Assim, ao lerem no texto " $O$ mais velho dos burros, que foi o primeiro a escolher, decidiu carregar o balaio maior, o mais pesado de todos, aquele que levava a comida dos homens. Os outros burros caíram na risada (...)", os alunos precisam estabelecer relações de causa e consequência, percebendo que a informação de que o burro mais velho foi o primeiro a escolher a carga e a informação de que o burro mais velho escolheu carregar o balaio mais pesado de todos consistem nas causas de outros burros, certamente mais novos, caírem na risada. $\mathrm{O}$ estabelecimento dessas relações permite que o aluno infira que os burros mais novos riram do burro mais velho porque ele, mesmo tendo a chance de escolher a carga mais leve, escolheu o balaio mais pesado, deixando a carga mais leve para os outros burros.

Também, para responder a questão "Explique o que aconteceu com a carga do burro mais velho durante a viagem”, faz-se necessário que o aluno construa inferências de ligação textual no último parágrafo do texto, considerando como causa o fato de os homens consumirem a comida do balaio que era levado pelo burro mais velho e como consequência o fato de a carga diminuir até o ponto de o balaio ficar vazio. A partir dessas relaçóes, tem-se uma resposta semelhante a: "Durante a viagem, a carga do burro mais velho foi diminuindo porque ele carregava a comida que ia sendo consumida pelos homens, até que em poucos dias o balaio foi ficando vazio. "É possível, entretanto, que os alunos, acostumados à prática de somente copiar informações presentes na superfície do texto, adotem a postura de apenas transcrever o início do último parágrafo: "Mas, à medida que a viagem seguia, a cada parada os homens serviam-se da comida do balaio do velho burro. Assim, em poucos dias, andava ele muito feliz e folgado, com seu balaio quase vazio. "Nesse caso, cabe ao professor da SAALP conduzir o aluno à reflexão das relações de causa e consequência presentes no parágrafo e não, simplesmente, admitir a mera transcrição realizada pelo aluno. Isso demonstra que a pergunta por si só não conduz ao estabelecimento das inferências; é preciso prestar auxílios aos alunos durante o processo da leitura, é necessário interação. 
Com relação à pergunta "Por que a carga dos burros mais novos não diminuiu durante a viagem?", a resposta também não se acha diretamente inscrita no texto. Para responder, o aluno precisa realizar inferências textuais e extratextuais (VIDAL-ABARCA; RICO, 2003), reunindo várias informações disponíveis no texto, por exemplo: o burro mais velho escolheu o balaio mais pesado; o balaio maior carregava a comida; os homens foram consumindo a comida que estava no balaio maior; o balaio foi ficando vazio durante a viagem - bem como, informações não explícitas, postas pelo leitor - o balaio, ao ficar vazio, foi ficando também leve, mais fácil de ser carregado; o balaio dos burros mais novos não carregava comida, mas possivelmente outras coisas como roupas, calçados, objetos de uso pessoal. A pergunta, assim, induz o aluno a levantar informações novas a partir de informações prévias, sendo elas textuais e não textuais, e a produzir uma resposta próxima a: "a carga dos burros mais novos não diminuiu durante a viagem porque os burros não carregavam a comida que era consumida pelos homens, mas outras coisas como sapatos, roupas etc.".

É importante salientar que, para que o aluno consiga responder a essas questôes inferenciais, ele deve saber primeiramente reconhecer as informações no texto; por isso, a importância das perguntas anteriores (a), (b) e (c) como etapa primeira do processamento do texto.

Consideramos que seria produtivo para esse contexto de ensino que o professor também separasse as perguntas de localização de informações das inferenciais para que o aluno percebesse que as modalidades tratam de dois processos diferentes, requerendo do leitor capacidades leitoras distintas, ou seja, a capacidade de decodificar aliando-se à compreensão; e a capacidade de ligar informações textuais e de relacionar informações textuais com informações do conhecimento prévio. Possivelmente, o professor uniu todas essas questôes em um mesmo bloco porque não lhe ficou claro, no desenvolvimento das ações colaborativas, a diferença entre os dois processos: localizar informaçōes e estabelecer inferências.

Outro aspecto que chama a atenção é que as perguntas textuais referemse ao primeiro parágrafo do texto e as inferenciais aos demais parágrafos. Avaliamos que essa organização compromete a construção dos sentidos textuais, pois as duas etapas, localização de informações e inferenciação, são concomitante e recursivamente utilizadas pelo leitor durante o processamento do texto (MENEGASSI, 2010c). Entendemos, assim, que outros dados textuais, presentes ao longo de todo o texto, podem ser trabalhados com os alunos por meio de perguntas de respostas textuais, para garantir que os 
processos de compreensão inferencial e interpretação sejam realizados adequadamente; por exemplo: "Que reação os burros mais novos tiveram diante da escolha do burro mais velho?"; "No decorrer da viagem, o que os homens faziam com a carga do burro mais velho?"; "Como ficou o balaio do burro mais velho após alguns dias de viagem?"; "Como ficou o balaio dos burros mais novos após alguns dias de viagem?" Ponderamos que esse problema ocorreu em virtude de que o modelo ao qual o professor foi exposto, no "Roteiro de discussão", com o texto "Escova de dentes: como fazíamos sem" e as questões propostas, apresentava uma organização semelhante, com perguntas textuais que abordavam exclusivamente a parte inicial do texto e perguntas inferenciais e interpretativas que trabalhavam o restante do material textual.

Nos dois blocos seguintes, aborda-se o nível interpretativo de leitura, com perguntas de elaboração pessoal, que auxiliam o aluno a constituir contrapalavras e reagir ativamente diante do enunciado (BAKHTIN/ VOLOCHINOV, 1999; BAKHTIN, 2003). Podem-se constatar também duas tipologias de perguntas: perguntas de interpretação textual e perguntas de interpretação extratextual (MENEGASSI, 2010a). Consideramos de interpretação textual aquelas que levam o leitor a tecer um parecer crítico a respeito de um determinado aspecto presente no texto. Exemplificam essa tipologia as perguntas: "Levando em conta os acontecimentos do texto, o que você pensa a respeito do comentário feito pelos burrinhos mais novos: 'Mas que burro! Quanto mais velho, mais burro...?"; "Na sua opiniāo, a opção do burro mais velho foi errada?", as quais requisitam a opinião do aluno acerca de passagens específicas do texto.

As perguntas de interpretação extratextual são aquelas que, partindo do texto, oportunizam ao aluno avaliar um aspecto da sociedade, instituindo, nos termos de Bakhtin/Volochinov (1926/1976), um diálogo do sujeito leitor com a própria situação extraverbal que o envolve. Na proposta em análise, isso se dá por meio da pergunta "No texto, os burros mais novos debocham, fazem gozação do burro mais velho. Esse tipo de atitude acontece em sua escola ou sala de aula?", que favorece um pensar crítico sobre o entorno social do aluno.

As questôes produzidas pelo professor nas etapas da decodificação, compreensão e interpretação, permitem que o aluno armazene as informações mais importantes na sua memória, ampliando significativamente seus conhecimentos, os quais poderão ser utilizados em leituras, produções textuais e reflexões futuras. Conforme Menegassi (2010c), a retenção de informações advinda da interpretação é mais enriquecedora do que a da compreensão, visto que se modificam os 
conhecimentos prévios não apenas com a soma de novas informações textuais, mas com o julgamento realizado pelo leitor a respeito do texto lido, o que propicia a construção de um novo texto, o texto do próprio leitor. No conjunto de perguntas produzidas pelo professor, propicia-se ao aluno tanto a oportunidade de armazenar informações textuais, no caso das perguntas (a) a (f), como também a possibilidade de reter informaçōes a partir da avaliação feita pelo aluno a respeito do texto e da sociedade - perguntas (g) a (i).

Em suma, a análise das perguntas de leitura produzidas pelo professor após as ações colaborativas permitem observar que:

- o professor demonstra ter internalizado conhecimentos acerca das etapas do processamento da leitura ao oferecer questôes que envolvem a localização de informações, a compreensão inferencial e a interpretação;

- expõe uma sequenciação e um ordenamento mais adequados à produção dos sentidos, partindo da localização de informações, passando pela produção de inferências, chegando à interpretação;

- ao formular as perguntas interpretativas, não desconsidera as etapas anteriores do processamento do texto e não cerceia a criatividade do aluno;

- contempla o conceito de leitura como processo e a noção conceitual de atividade.

No esteio do conceito de leitura como réplica e como um processo que se dá em etapas, as perguntas oferecidas aos alunos da SAALP mostram-se mais eficazes para a formação e o desenvolvimento do leitor, visto que requisitam do aluno o trabalho de construção do significado do texto, partindo de níveis mais elementares da leitura, passando pela etapa da compreensão inferencial até chegar aos níveis mais complexos.

\section{Considerações finais}

Ao analisarmos os questionários de leitura trabalhados na SAALP, constatamos que faltava ao professor conhecimentos mais aprofundados a respeito das etapas do processamento da leitura, visto que as perguntas restringiam-se ao nível interpretativo, desconsiderando-se os níveis textual e inferencial, basilares do processo de compreensão do texto. Verificamos, ainda, ordenação e sequenciação aleatórias das perguntas oferecidas em sala de aula, bem como uma formulação precária dos comandos, de maneira a comprometer a construção dos sentidos pelo aluno. 
Após as açōes colaborativas desenvolvidas junto ao professor, que se pautaram na discussão acerca do caráter processual da leitura, percebemos alterações na prática de produção de perguntas. Ao levar em consideração as etapas do processamento da leitura, o professor passou a trabalhar perguntas textuais, inferenciais e interpretativas, a ordenar e sequenciar as perguntas de modo a orientar o aluno na produção dos sentidos ao texto trabalhado e, desse modo, a propiciar condições para que ele se aproprie ativamente das "palavras alheias", some a essas palavras as vivências individuais e produza "palavras próprias", com aspecto de novidade (BAKHTIN, 2003).

Os resultados das análises apontam para a necessidade de se fornecer ao professor de SAALP subsídios teóricos a respeito do processo da leitura, bem como acompanhar e orientar a sua prática pedagógica com a elaboração de perguntas de leitura nesse contexto de ensino.

\section{Referências}

ANGELO, C. M. P.; MENEGASSI, R. J. Manifestaçôes da compreensão responsiva na leitura. Linguagem \& Ensino. Pelotas, v.14, n.1, p.201-221, jan./jun. 2011. Disponível em: <http://www.rle.ucpel.tche.br/index.php/rle/article/view/14>. Acesso em: 4 abr. 2013.

BAKHTIN, M. M. Estética da criação verbal. Tradução do russo por Paulo Bezerra. 4.ed. São Paulo: Martins Fontes, 2003.

BAKHTIN, M. M.; VOLOCHINOV, V. N. Discurso na vida e discurso na arte (sobre poética sociológica). Tradução de Carlos Alberto Faraco e Cristóvão Tezza [para fins didáticos]. Versão da língua inglesa de I. R. Titunik a partir do original russo, 1926.

BAKHTIN, M. M.; VOLOCHINOV, V. N. Marxismo e filosofia da linguagem: problemas fundamentais do método sociológico na ciência da linguagem. Tradução do francês por Michel Lahud e Yara Frateschi Vieira. 9.ed. São Paulo: Hucitec, 1999.

BARROS, D. L. P. de. Contribuições de Bakhtin às teorias do texto e do discurso. In: FARACO, C. A.; TEZZA, C.; CASTRO, G. de (Org.). Diálogos com Bakhtin. Curitiba: UFPR, 1996. p.21-42.

CERQUEIRA, M. S. de. Atividade versus exercício: concepçôes teóricas e a prática da produção textual no ensino de língua portuguesa. Trabalhos em Linguistica Aplicada, Campinas, v.49, n.1, June 2010. Disponível em: <http://www. scielo. br/scielo.php?pid=S0103-18132010000100010\&script=sci_arttext $>$. Acesso em: 6 maio 2013. 
CLARK, K; HOLQUIST, M. O Marxismo e a Filosofia da Liguagem. In: Mikhail Bakhtin. Trad. de J. Guinshuy. São Paulo: Perspectiva, 2004. p. 233-255. CURADO, O. H. F. Linguagem dialógica: práticas de leitura e produção de texto. In: OSORIO, E. M. R. (Org.). Mikhail Bakhtin: cultura e vida. São Carlos: Pedro \& João Editores, 2010. p.141-151.

FARACO, C. A. Linguagem e diálogo: as ideias linguísticas do círculo de Bakhtin. Curitiba: Criar Edições, 2003.

JESUS, D. M.; ALMEIDA, M. L.; SOBRINHO, R. C. Pesquisa-ação-críticocolaborativa: implicações para a formação continuada e a inclusão escolar. Anais... Minicurso apresentado na 28a Reunião Anual da Anped, Caxambu/MG, 2005.

MAGALHÃES, M. O professor de línguas como pesquisador de sua ação: a pesquisa colaborativa. In: GIMENEZ, T. (Org.). Trajetórias na formação de professores de linguas. Londrina: UEL, 2002. p.39-55.

MARCUSCHI, L. A. Compreensão de texto: algumas reflexões. In: DIONISIO, A. P. \& BEZERRA, M. A. O livro didático de Português: múltiplos olhares. Rio de Janeiro: Lucerna, 2001.

MENEGASSI, R. J. Avaliação de leitura. In: MENEGASSI, R. J. (Org.). Leitura e ensino. 2.ed. Maringá: Eduem, 2010a. p.87-106.

MENEGASSI, R. J. Perguntas de leitura. In: MENEGASSI, R. J. (Org.). Leitura e ensino. 2.ed. Maringá: Eduem, 2010b. p.167-189.

MENEGASSI, R. J. O leitor e o processo de leitura. In: GRECO, E. A.; GUIMARÃES, T. B. (Org.). Leitura: aspectos teóricos e práticos. Maringá: Eduem, 2010c. p.35-59.

MENEGASSI, R. J. Produção, ordenação e sequenciação de perguntas na avaliação de leitura. In: CENTURION, R.; CRUZ, M.; BATISTA, I. M. (Org.). Linguagem $e(m)$ interação-Linguas, literaturas e educação. Cáceres-MT: Ed. Unemat, 2011, p. 17-35.

RODRIGUES, A. Perguntas de leitura e construção de sentidos: experiência com o $6^{\circ}$ ano do Ensino Fundamental. Maringá: UEM, 2013. Dissertação (Mestrado em Letras) - Programa de Pós-Graduação em Letras, Universidade Estadual de Maringá, Maringá, 2013.

ROJO, R. Letramento e capacidades de leitura para a cidadania. São Paulo: SEE: CENP, 2004. Disponível em: http://suzireis.bravehost.com/posgraduacao/artigos/ roxane_rojo.pdf>. Acesso em: 20 nov. 2010.

ROJO, R. Letramentos múltiplos, escola e inclusão social. São Paulo: Parábola Editorial, 2009. 
SOLÉ, Isabel. Estratégias de leitura. Trad. Claudia Schilling. Porto Alegre: Ed. Artmed, 1998.

TAGLIEBER, L. K; PEREIRA, C. M. Atividades de pré-leitura. Gragoatá, Niterói, (2): 73-92; $1^{\circ}$ sem. 1997.

TERZI, S. B. A construção da leitura: uma experiência com crianças de meios iletrados. Campinas: Pontes/Ed. Unicamp, 1995.

VIDAL-ABARCA, E.; RICO, G. M. Por que os textos são tão difíceis de compreender? As inferências são a resposta. In: TEBEROSKY, A.; OLLER, C. Compreensão de leitura: a língua como procedimento. Porto Alegre: Artmed, 2003. p.139-154.

Data de submissão: 12/12/2013. Data de aprovação: 13/05/2014. 
